\title{
MUCORMYCOSIS, THE BLACK FUNGUS ALARMING COINFECTIONS IN COVID-19 PATIENTS
}

\author{
Shahid Nawaz*, Maira Saleem \\ Institute of Microbiology and Molecular Genetics, University of the Punjab Lahore Pakistan. \\ *Corresponding author \\ Email. shahidnawaz.phd.mmg@pu.edu.pk
}

\section{Background}

The severe acute respiratory syndrome coronavirus 2 (SARS-CoV-2) has emerged as a global pandemic causing coronavirus disease 2019 (COVID-19). It was firstly reported in Hubei province in the People's Republic of China and spread worldwide quickly. The COVID-19 affects every person differently, from mild to life-threatening symptoms (Nawaz, 2020), along with other bacterial or fungal co-infections (CDC., 2021). The COVID-19 affected patients are prone to develop severe opportunistic infections (Salehi et al., 2020). The immune system of SARS-COV-2 infected patients becomes vulnerable to these opportunistic infections if some comorbidities (diabetes, pulmonary disease) or immunocompromised conditions (steroid therapy, hospital stay, and ventilation) are present. The development of infections such as Pneumocystis jiroveci pneumonia, bloodstream candida, pulmonary aspergillosis, and oropharyngeal candidiasis have been reported in SARS-CoV-2 infected patients (Moorthy et al., 2021). A few case reports of rhino-orbital mucormycosis in COVID-19 have been reported (Mehta et al., 2020). One such study was reported by (Sen et al., 2021), in which they presented a series of six cases of COVID-19 disease with rhino-orbital mucormycosis. Only one patient in this series had concurrent COVID-19 and mucormycosis at hospital admission, while five patients developed mucormycosis during treatment for COVID-19. Recent studies in Pakistan have reported an increased number of cases of mucormycosis, also known as "black fungus" in COVID-19 patients (The News., 2021).

\section{Main text}

Mucormycosis is a life-threatening infection caused by fungi in the order Mucorales, spread rapidly through the infiltration of blood vessels, and can be of two kinds: acute or subacute. Mucormycosis can lead to morbidity and mortality in immunocompromised patients and those with poorly controlled diabetes mellitus. It affects the nose, paranasal sinus, and brain. The brain infection can lead to two conditions: rhino-orbital mucormycosis or rhino-cerebral 
mucormycosis. In the COVID-19 pandemic, most reported cases to belong to rhino-orbital mucormycosis (Bakshi et al., 2019; John et al., 2021). Some pulmonary and gastrointestinal mucormycosis cases have also been reported (do Monte et al., 2020; Garg et al., 2021). The exact cause of increased mucormycosis infection cases in COVID-19 patients is still unknown, but certain factors could have played the role, such as; immunocompromised conditions due to the pre-existing diseases, immunosuppressive drug therapy, immune alterations by the SARS-CoV-2, and pre-existing poor lung conditions (Reid et al.,2020). In India, people have also used cow dung as a part of treatment for Covid-19. However, rubbing cow dung has been thought to play a role in the spread of mucormycosis in Covid-19 patients (The print., 2021). The COVID-19 pandemic has put immense pressure on the health care system and has made it challenging to manage mucormycosis. The successful management of mucormycosis is based on; early detection, controlled hyperglycemia, surgical debridement, and liposomal amphotericin B. However, it is not easy to control hyperglycemia in the current pandemic situation because of the extensive use of steroids in the COVID-19 treatment. The workforce and other resources have been shifted to other departments during the pandemic, thus, causing delayed surgical debridement in operation theaters. The multi-organ dysfunction exists in these patients, making it difficult to shift them for imaging studies (BBC, 2021).

\section{Conclusion}

The co-infection of mucormycosis and COVID-19 is an alarming situation. Thus, clinicians should be sensitized to the risk of this fatal co-infection. Proper care should be given to the COVID-19 patients with pre-existing diabetes while treating them with systemic steroids. Moreover, careful administration of glucocorticoids must be advocated in all patients. Pakistan being a neighboring country of India, should take extra measures to contain black fungus infections in COVID-19 recovered patients; because of the lower immunity, there are more chances that the recovered individuals may become victims of black fungus.

\section{References}

Bakshi, S. S. 2019. Rhino-orbital mucormycosis. Bulletin of Emergency and Trauma, 7(1):8889. 
do Monte Junior, E. S., Santos MELD, Ribeiro IB, Luz G d O, Baba ER, Hirsch BS et al (2020) Rare and fatal gastrointestinal mucormycosis (zygomycosis) in a COVID-19 patient: a case report. Clinical Endoscopy, 53(6):746-749.

Garg, D., Muthu, V., Sehgal, I. S., Ramachandran, R., Kaur, H. and Bhalla, A. 2021. Coronavirus disease (Covid-19) associated mucormycosis (CAM): case report and systematic review of literature. Mycopathologia, 5:1-10.

https://theprint.in/health/doctors-hint-at-cow-dung-black-fungus-link-as-people-turn-togobar-for-covid-cure/657781/

https://www.bbc.com/news/world-asia-india-57167322

https://www.cdc.gov/fungal/covid-fungal.html

https://www.thenews.com.pk/print/834117-cases-of-black-fungus-emerge-across-pakistan

John, T. M., Jacob, C. N. and Kontoyiannis, D. P. 2021. When uncontrolled Diabetes mellitus and severe COVID-19 converge: the perfect storm for mucormycosis. Journal of Fungi, 7(4):298.

Mehta, S. and Pandey, A. 2020. Rhino-Orbital Mucormycosis Associated With COVID-19. Cureus. 12(9):e10726. doi:10.7759/cureus.10726.

Moorthy, A., Gaikwad, R., Krishna, S. et al. SARS-CoV-2, Uncontrolled Diabetes and Corticosteroids - An Unholy Trinity in Invasive Fungal Infections of the Maxillofacial Region? A Retrospective, Multi-centric Analysis. J. Maxillofac. Oral Surg. (2021). https://doi.org/10.1007/s12663-021-01532-1

Nawaz, S. 2020. Covid-19, SARS -CoV-2, Origin, transmission and treatment aspects, a brief review. Infectious Disorders- Drug Targets. doi: $10.2174 / 1871526520666201006163641$.

Reid, G.; Lynch, J. P.; Fishbein, M. C.; Clark, N.M. 2020. Mucormycosis. Seminars in Respiratory and Critical Care Medicine, 41:99-114. 
Salehi, M., Ahmadikia, K., Badali, H. and Khodavaisy, S. 2020. Opportunistic fungal infections in the epidemic area of COVID-19: A clinical and diagnostic perspective from Iran. Mycopathologia, 185(4):607-611.

Sen, M., Lahane, S., Lahane, T. P., Parekh, R. and Honavar, S. G. 2021. Mucor in a viral land: A tale of two pathogens. Indian Journal of Ophthalmology, 69(2):244-252. 